\title{
The effect of sodium and potassium fertilizer on the mineral composition of sugar beet
}

\author{
BY S. N. ADAMS \\ Rothamsted Field Station, Dunholme, Lincoln
}

(Received 26 October 1960)

\begin{abstract}
This paper describes work done at Rothamsted in 1942 and 1943 by the late Dr J. B. Hale. The results were left in manuscript by $\mathrm{Dr}$ Hale and, as they contain information of a type which does not soon become out of date, it was thought worthwhile to rewrite and publish them.
\end{abstract}

\section{INTRODUCTION}

Between 1929 and 1939, English experiments showed that salt increased the yield of sugar beet (Rothamsted Annual Report 1937). In 1940, salt was introduced as an additional treatment in an existing series of $3^{3}$ factorial NPK trials being done each year in the British sugar-growing regions. The design was altered to $2^{4}$ factorial and salt was given at rates of 0 and 5 cwt./acre. In 1940-45, 5 cwt./selt gave an average response of $4.8 \mathrm{cwt}$. sugar/acre and 0.78 ton tops/acre.

The experiments, which were on soils of a wide range of textures, provided consistent evidence that salt increases the yield of sugar beet. It was not clear, however, whether sodium acted by replacing potassium in the soil and thus making more potassium available to the plant, or directly as a plant nutrient. To answer this question, samples of tops and roots were taken from all plots in 1941-45 and analysed for potassium and sodium. The mean of all experiments showed that a sugar-beet crop of 11.45 tons roots and 9.42 tons tops/acre contains 1.44 cwt. $\mathrm{K}_{2} \mathrm{O}$ and $0.72 \mathrm{cwt}$. $\mathrm{Na}_{2} \mathrm{O}$. The 5 cwt./acre dressing of salt on average increased the crop's sodium content by $0.29 \mathrm{cwt}$. $\mathrm{Na}_{2} \mathrm{O} / \mathrm{acre}$, but reduced the uptake of potassium by 0.011 cwt. $\mathrm{K}_{2} \mathrm{O}$ /acre. Salt does not therefore increase the potassium content of the crop, and the conclusion was that sodium acts directly as a nutrient for sugar beet.

In 1942 and 1943 a Rothamsted experiment compared the effects of muriate of potash and salt on sugar beet, and material from it was used for a joint chemical and physiological investigation. Plant samples were taken throughout the growing season to determine leaf area, dry matter and content of $\mathrm{N}, \mathrm{K}, \mathrm{Na}, \mathrm{Ca}, \mathrm{Mg}$ and $\mathrm{Mn}$. This paper describes only the chemical results.

\section{DESCRIPTION OF THE EXPERIMENTS}

The experimental treatments were all combinations of: $0,2 \frac{1}{2}, 5,7 \frac{1}{2}$ cwt. salt/acre; $0,1,2$ cwt. $\mathrm{K}_{2} \mathrm{O}$ /acre as muriate of potash; Salt applied to the seed-bed versus salt applied in winter before ploughing.

There were two replicates and twenty-two treatments, and the potash dressings were adjusted so that the 2 cwt. $\mathrm{K}_{2} \mathrm{O}$ level was chemically equivalent to $2 \frac{1}{2} \mathrm{cwt}$. salt/acre. All plots received $0.8 \mathrm{cwt}$. $\mathrm{N} /$ acre as sulphate of ammonia and 0.6 cwt. $\mathrm{P}_{2} \mathrm{O}_{5} /$ acre as superphosphate.

\section{SAMPLING}

As the plots were required for yield at harvest, samples for analysis could be taken only from a small part at the end of each plot. There were 15 rows per plot. The edge rows were ignored and three neighbouring plants were taken from each of two rows working inwards on successive occasions-i.e. rows 2 and 14 were sampled the finst time, rows 3 and 13 the next and so on. The first sample in 1943 was taken before singling by removing twenty plants at random from the whole plot. Sampling dates were:

$\begin{array}{lcr} & 1942 & 1943 \\ \text { I } & \text { 16 July } & \text { 1 June } \\ \text { II } & \text { 30 July } & \text { 24 June } \\ \text { III } & 20 \text { Aug. } & 16 \text { July } \\ \text { IV } & 10 \text { Sept. } & \text { 6 Aug. } \\ \text { V } & 1 \text { Oct. } & 26 \text { Aug. } \\ \text { VI } & 29 \text { Oct. } & 23 \text { Sept. } \\ \text { VII } & \text { - } & 20 \text { Oct. }\end{array}$

Plants were lifted and topped by hand, the crown of the root being included in the tops. The number of leaves was counted and the laminae cut from the petioles and weighed. The laminae were heaped at random and disks cut from them by boring holes with a cork borer of known cross-sectional area. About 100 disks were weighed and counted, giving an estimate of leaf area per unit weight. Roots and petioles were subsampled by cutting a wedge-shaped section from each. Thus three subsamples per plot 
were obtained which were oven-dried at $90^{\circ} \mathrm{C}$. and weighed. Samples from the replicates and the different times of salt application were bulked to leave twelve samples for chemical analysis corresponding to the twelve rates of salt and potash treatments. The bulked samples were ground in a hammer mill.

\section{METHODS OF ANALYSIS}

Nitrogen was estimated by a micro-Kjeldahl method using $100 \mathrm{mg}$. dry material, $0.75 \mathrm{ml}$. concentrated sulphuric acid and an 8:1:1 $\mathrm{K}_{2} \mathrm{SO}_{4}$, $\mathrm{CuSO}_{4}, \mathrm{SeO}_{2}$ catalyst. The distillate was collected in $2 \%$ boric acid and titrated with $\mathrm{N} / 28 \mathrm{HCl}$ using a methyl red-bromocresol green indicator.

$K, \mathrm{Na}, \mathrm{Ca}, \mathrm{Mg}$ and $M n$ were determined spectrographically, using the Lundegardh flame apparatus with a Hilger medium quartz spectrograph (f $60 \mathrm{~cm}$ ). $1.25 \mathrm{~g}$. dry material was extracted with $50 \mathrm{ml}$. $\mathrm{N}-\mathrm{HCl}$ for $24 \mathrm{hr}$. and the filtrate, diluted as necessary, was suitable for all estimations without further treatment. The lines $\mathrm{Ca} 4227 \mathrm{~A}, \mathrm{~K} 4044 \mathrm{~A}, \mathrm{Mn} 4031 \mathrm{~A}$, Na 3303 A, Mg 2852A were used with Ilford Zenith plates. When there was less than $0.1 \% \mathrm{Na}_{2} \mathrm{O}$ in the dry material, the $\mathrm{Na}$ doublet $5890 / 96 \mathrm{~A}$ was used with Ilford Iso-Zenith plates. All analyses are expressed on a dry-matter basis.

\section{RESULTS OF THE EXPERIMENTS}

The total uptake of nutrients

Fig. 1 shows the total uptake of all nutrients averaged over all treatments. When measurements were started early enough, as in 1943, the curves are S-shaped, like dry-matter growth curves. Appreciable uptake of $\mathrm{N}$ and $\mathrm{Mn}$, however, was still taking place at the end of the season, especially in 1943. Some nutrients were lost in autumn. The highest sodium content was reached in early September in both years and calcium and potassium contents declined in the autumn of 1942 . Nutrient losses may occur by either the death and loss of old leaves or by excretion into the soil, but dead leaves


Fig. 1. The nutrient content of sugar beet during the growing season. 


\section{Sodium and potassium fertilizer and composition of sugar beet}

were not collected and analysed so there is no direct evidence on the relative importance of the two mechanisms.

\section{The distribution of nutrients in the plant}

Fig. 2 shows the change in mineral composition of all parts of the plant with time of year, averaged over all treatments. Except manganese and, sometimes, magnesium, the concentration of elements in the dry matter falls throughout the growing season. The fall is fastest in the root and slowest in the laminae. The first sampling in 1943 was at the singling stage and 6 weeks earlier than in 1942. The concentration of nutrients in the root, but not in the lamina or petiole, fell most rapidly in the first 3-6 weeks after singling. Nutrient concentrations were higher in the lamina than in the petiole, except for potassium at the beginning of the season.

Manganese is exceptional and its concentration rises during the season. In the root in 1943, a sharp fall in concentration in the first weeks after singling was followed by a slow rise for the rest of the season. In 1943, the magnesium concentration in the lamina also rose until the last sampling.

Table 1 shows the distribution of the nutrients in the plant at three different dates. At singling time, approximately $75 \%$ of the total amount of an element was in the lamina. At the end of the season, all elements except sodium were approximately equally divided between lamina, petiole and root. Only $6 \%$ of the sodium was in the root, the remainder being equally divided between lamina and petiole.

\section{The effect of fertilizer treatments on plant composition}

Fig. 3 shows the effect of the fertilizer treatments on $\% \mathrm{~K}_{2} \mathrm{O}$ and $\mathrm{Na}_{2} \mathrm{O}$ in the plant averaged over all sampling times. As would be expected, potash increases $\% \mathrm{~K}_{2} \mathrm{O}$ and salt increases $\% \mathrm{Na}_{2} \mathrm{O}$ in all parts of the plant. Except for potash in 1942, the first increment of fertilizer gave the biggest increase in mineral content of the plant and typical response curves were obtained.

Potash application decreased $\% \mathrm{Na}_{2} \mathrm{O}$ in the plant, but the effect of salt on potassium concentration was more complex. On average, salt decreased $\% \mathrm{~K}_{\mathbf{2}} \mathrm{O}$ in the lamina but increased it in the roots. The increase in the root was observed at all sampling times in both years. Salt decreased $\% \mathrm{~K}_{2} \mathrm{O}$ in the petiole early in the season but increased it in the later harvests. The change took place at the end of August in 1942 but at the end of July, and more sharply, in 1943.

The interaction between salt and potash affected $\% \mathrm{Na}_{2} \mathrm{O}$, but not $\% \mathrm{~K}_{2} \mathrm{O}$. Potash increased $\% \mathrm{Na}_{2} \mathrm{O}$ in the lamina when no salt was given but decreased it in the presence of high dressings. Similar trends were shown by the petiole and root, although even when salt was not given potash decreased $\% \mathrm{Na}_{2} \mathrm{O}$, in the petiole in 1942 and the root in 1943 . In both years, selt increased $\% \mathrm{Na}_{8} \mathrm{O}$ more when no potash was given.

The yields on the main plots of the experiment, summarized in the Results of the Rothamsted Field Experiments 1939-47, showed that potesh, averaged over all levels of salt, did not significantly affect yield of roots and tops in either year. The effect of potash on the sodium and potassium content of the plant, therefore, is similar to the effect on nutrient concentration shown in Fig. 4.

Salt, however, significantly increased root yield in both years and yield of tops in 1942. Thus, although salt decreases the potassium concentration in the plant (Fig. 3) it does not decrease uptake. Table 2 shows the effect of salt on potassium uptake, averaged over all sampling times. In 1942, dressings of 2.5 and $5.0 \mathrm{cwt}$. salt/acre increased the potassium content in the petiole and root but decreased that of the lamina. The total uptake of potash was, however, increased. Results in 1943 were similar, but the total potassium uptake was not affected by salt in that year.

\section{DISCUSSION}

The 1942 and 1943 seasons, although drier than average, were favourable for sugar beet at Rothamsted. In both years, yields on the main plots of the experiment were over 16 tons/acre of washed beet of over $18 \%$ sugar content. The uptake of all nutrients was greatest in July and August, which is later than for most other British annual crops. Sugar-beet fertilizer is usually applied 4-5 months before this period of maximum uptake, so deficiencies of mobile nutrients might occur in late summer. However, neither early (Sykes, 1931) nor recent experiments (Adams, 1960) showed any advantage from applying nitrogenous top dressings to sugar beet.

Manganese continues to be taken up until late autumn, and the final manganese content is equivalent to about $7 \mathrm{lb}$./acre of manganous sulphate. Manganese deficiency symptoms are often prevented by spraying manganous sulphate in May or June, although there is little evidence that the spray increases yield. The extent and time of manganese absorption shown by these experiments suggest, however, that the spraying is theoretically reason. able. By contrast, the final magnesium content of the plant is equivalent to about $200 \mathrm{lb}$./acre of epsom salts. Clearly there is little hope of supplying such a large quantity by spraying after the appearance of deficiency symptoms. The application before sowing of a fertilizer containing magnesium seems more appropriate for this nutrient.

Salt increased yield in the experiments, but there is no evidence that it acted by replacing potassium 
A. 1942
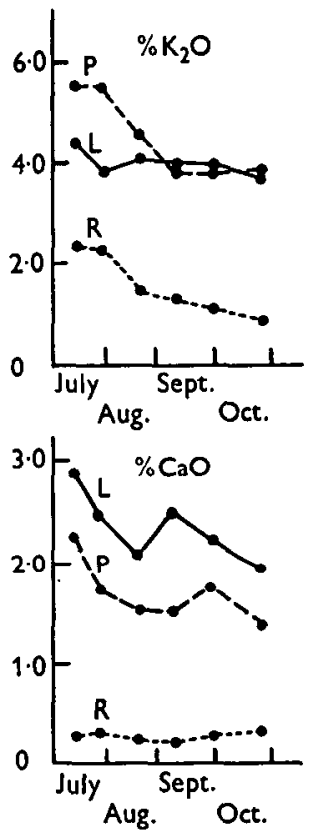

0
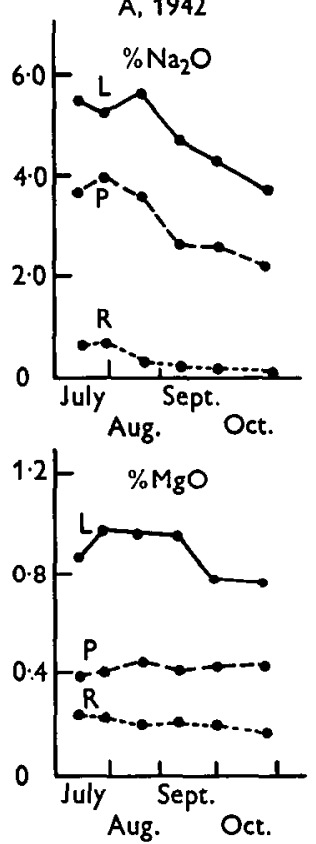

B, 1943
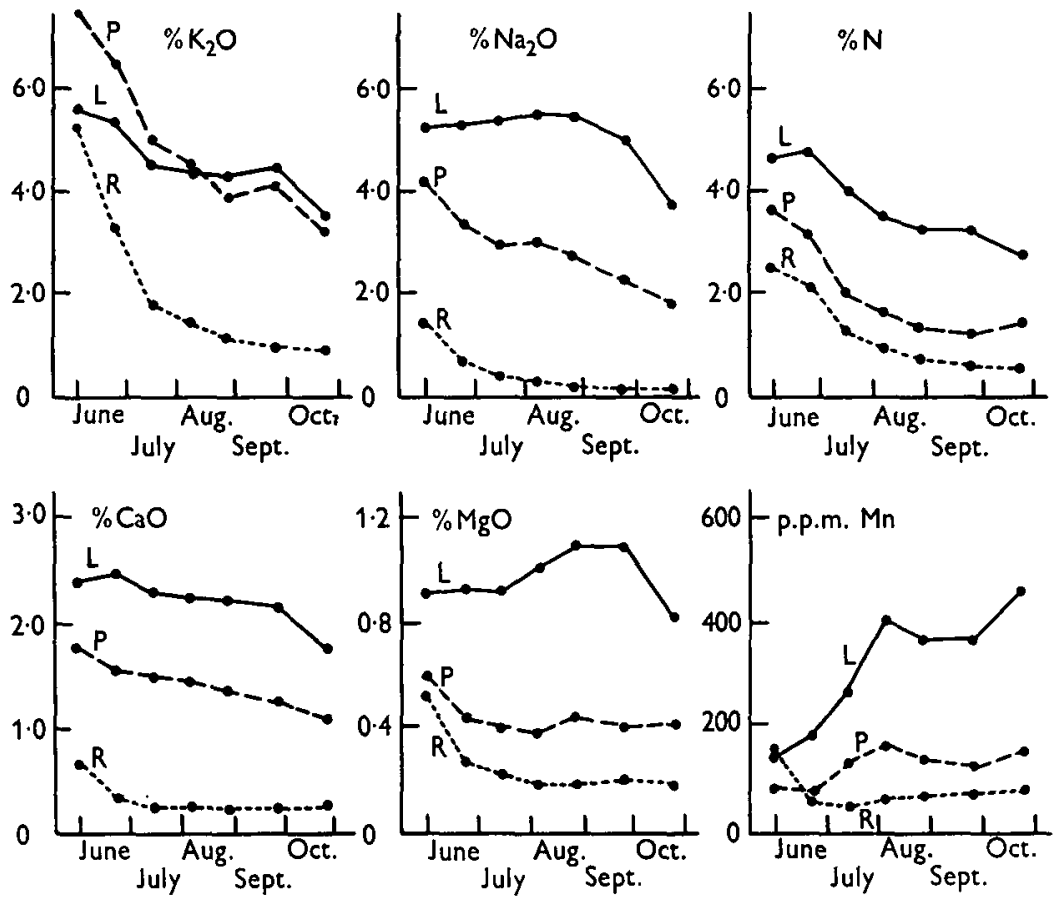

Fig. 2. The mineral content of the dry matter of sugar beet laminae, petioles and roots. 
Table 1. Distribution of nutrients in the plant expressed as percentage of total plant content

\begin{tabular}{|c|c|c|c|c|c|c|c|c|c|c|c|c|}
\hline \multirow[b]{2}{*}{ Loming } & \multicolumn{2}{|c|}{$\mathrm{N}$} & \multicolumn{2}{|c|}{$\mathrm{K}_{2} \mathrm{O}$} & \multicolumn{2}{|c|}{$\mathrm{Na}_{2} \mathrm{O}$} & \multicolumn{2}{|c|}{$\mathrm{CaO}$} & \multicolumn{2}{|c|}{$\mathrm{MgO}$} & \multicolumn{2}{|c|}{$\mathrm{Mn}$} \\
\hline & 1942 & 1943 & 1942 & 1943 & 1942 & 1943 & 1942 & 1943 & 1942 & 1943 & 1942 & 1943 \\
\hline $\begin{array}{l}1 \text { June } \\
\text { Early Aug. } \\
\text { End Oct. }\end{array}$ & $\begin{array}{l}-\overline{56} \\
34\end{array}$ & $\begin{array}{l}73 \\
48 \\
34\end{array}$ & $\begin{array}{l}\overline{35} \\
23\end{array}$ & $\begin{array}{l}63 \\
35 \\
25\end{array}$ & $\begin{array}{l}-58 \\
41\end{array}$ & $\begin{array}{l}76 \\
60 \\
51\end{array}$ & $\begin{array}{l}-\overline{60} \\
30\end{array}$ & $\begin{array}{l}78 \\
53 \\
\mathbf{3 4}\end{array}$ & $\begin{array}{l}-\overline{63} \\
31\end{array}$ & $\begin{array}{l}77 \\
\mathbf{5 5} \\
\mathbf{3 2}\end{array}$ & $\begin{array}{l}\overline{70} \\
34\end{array}$ & $\begin{array}{l}73 \\
57 \\
42\end{array}$ \\
\hline $\begin{array}{l}\text { Petiole } \\
\text { I June } \\
\text { Early Aug. } \\
\text { End Oct. }\end{array}$ & $\begin{array}{l}\overline{23} \\
28\end{array}$ & $\begin{array}{l}19 \\
21 \\
29\end{array}$ & $\begin{array}{l}\overline{40} \\
48\end{array}$ & $\begin{array}{l}\mathbf{2 8} \\
\mathbf{3 7} \\
\mathbf{3 9}\end{array}$ & $\begin{array}{l}\overline{34} \\
53\end{array}$ & $\begin{array}{l}20 \\
32 \\
42\end{array}$ & $\begin{array}{l}\overline{32} \\
43\end{array}$ & $\begin{array}{l}19 \\
33 \\
39\end{array}$ & $\begin{array}{l}\overline{20} \\
34\end{array}$ & $\begin{array}{l}16 \\
21 \\
28\end{array}$ & $\begin{array}{l}-16 \\
29\end{array}$ & $\begin{array}{l}15 \\
22 \\
23\end{array}$ \\
\hline $\begin{array}{l}\text { Root } \\
1 \text { June } \\
\text { Early Aug. } \\
\text { End Oct. }\end{array}$ & $\begin{array}{l}\overline{21} \\
38\end{array}$ & $\begin{array}{r}7 \\
31 \\
37\end{array}$ & $\begin{array}{l}\overline{25} \\
29\end{array}$ & $\begin{array}{r}9 \\
28 \\
\mathbf{3 5}\end{array}$ & $\begin{array}{l}-8 \\
5\end{array}$ & $\begin{array}{l}3 \\
7 \\
6\end{array}$ & $\begin{array}{r}-8 \\
26\end{array}$ & $\begin{array}{r}3 \\
14 \\
27\end{array}$ & $\begin{array}{l}\overline{17} \\
35\end{array}$ & $\begin{array}{r}7 \\
24 \\
39\end{array}$ & $\begin{array}{l}\overline{13} \\
37\end{array}$ & $\begin{array}{l}12 \\
21 \\
35\end{array}$ \\
\hline
\end{tabular}
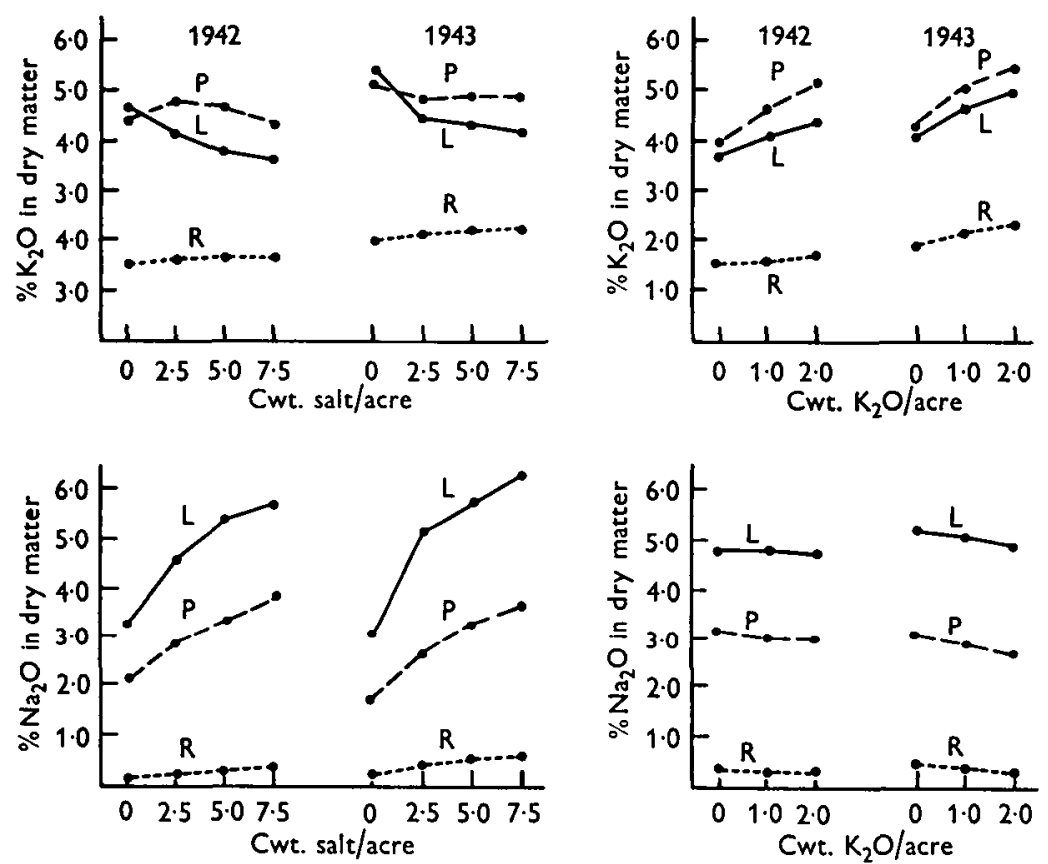

Fig. 3. The effect of salt and potash application ou plant $\mathrm{Na}_{2} \mathrm{O}$ and $\mathrm{KO}_{2}$ concentration; average of all sampling times.

Table 2. The effect of salt on potassium content

(Total $\mathrm{K}_{2} \mathrm{O}$ (g/plant) averaged over all sampling times.)

1942 ,

cwt. salt/acre

\begin{tabular}{lllll} 
Lamina & $\mathbf{0 . 9 4}$ & 0.85 & 0.82 & 0.74 \\
Petjole & $\mathbf{1 . 1 4}$ & $\mathbf{1 . 3 5}$ & $\mathbf{1 . 4 6}$ & $\mathbf{1 . 3 4}$ \\
Root & $\mathbf{0 . 6 8}$ & $\mathbf{0 . 8 7}$ & $\mathbf{0 . 9 8}$ & $\mathbf{0 . 9 0}$ \\
\multicolumn{1}{c}{ Total } & $\mathbf{2 . 7 6}$ & $\mathbf{3 . 0 7}$ & $\mathbf{3 . 2 6}$ & $\mathbf{2 . 9 8}$
\end{tabular}

$7 \cdot 5$
$0 \cdot 74$
$1 \cdot 34$
$0 \cdot 90$
$2 \cdot 98$

\begin{tabular}{|c|c|c|c|}
\hline & \multicolumn{2}{|c|}{$\begin{array}{c}1943, \\
\text { cwt. salt/acre }\end{array}$} & \\
\hline 0 & $2 \cdot 5$ & $5 \cdot 0$ & $7 \cdot 5$ \\
\hline $\begin{array}{l}0.78 \\
0.73 \\
0.55\end{array}$ & $\begin{array}{l}0.70 \\
0.81 \\
0.67\end{array}$ & $\begin{array}{l}0.63 \\
0.80 \\
0.65\end{array}$ & $\begin{array}{l}0.59 \\
0.80 \\
0.66\end{array}$ \\
\hline $2 \cdot 06$ & $2 \cdot 18$ & $2 \cdot 08$ & $2 \cdot 05$ \\
\hline
\end{tabular}


in the soil and so mobilizing soil potash reserves. In 1942, salt applications up to $5.0 \mathrm{cwt}$./acre did increase potassium uptake but this was because salt increased the dry matter. The potassium concentration of the whole plant was not increased. Moreover, when the potassium concentration and uptake of the plant was increased directly by applying potash fertilizer, no yield increase was obtained.

The sodium was distributed in the plant quite differently from potassium. The small concentration of sodium in the roots at all harvests is notable. Furthermore, the potassium concentration in the petiole is higher than in the lamina in the early harvests, but the sodium content of the lamina always exceeds that of the petiole.

The results therefore support the view that sodium is a nutrient for beet and not a potassium substitute.

\section{SUMLMARY}

Plants from salt and potash fertilizer trials at Rothamsted were harvested at intervals throughout the growing seasons of 1942 and 1943 and analysed for $\mathrm{N}, \mathrm{K}, \mathrm{Na}, \mathrm{Ca}, \mathrm{Mg}$ and $\mathrm{Mn}$.

The uptake of nutrients is discussed with respect to field methods of fertilizer application.

Salt increased beet yield in both years, but it did not act by mobilizing soil potassium reserves and increasing the potassium status of the plant. Potash fertilizer, although increasing the potassium status of the plant, did not increase yield. Sodium and potassium were differently distributed in the plant. At harvest, only $6 \%$ of the plant's sodium content was in the root compared with $33 \%$ of the potassium. The potassium, but not the sodium content of the petiole, was higher than that of the lamina until the end of August. Sodium thus is a nutrient for beet and not a potassium substitute.

I thank Dr G. W. Cooke who drew my attention to Dr Hale's manuscript and who has given much helpful advice in the preparation of the paper.

\section{REFERENCES}

Adams, S. N. (1960). J. Agric. Sci. 54, 395.

Annual Report Rothamsted Experimental Station (1937), pp. 41-42.

Sykes, E. T. (1931). J. Minist. Agric. 38, 162. 